\title{
In vivo Study of Use of Bioceramic Material in Open Crown-root Fractures
}

\author{
ANCA MELIAN, GABRIEL MELIAN, CATALINA IULIA SAVEANU*, SORINA MIHAELA SOLOMON, \\ CRISTIAN LEVENTE GIUROIU, MIHAELA SĂLCEANU \\ Faculty of Dental Medicine, University of Medicine and Pharmacy Gr.T.Popa, 16 Universitatii Str., 700115, Iasi, Romania
}

Treatment of crown root fracture is complex and requires an accurate diagnostic and treatment plan. The purpose of this article is to report a case of a maxillary central incisor with a crown-root fracture with pulp exposure treated and rehabilitated with the preservation of pulp vitality using a micro-pulpotomy and pre-mixed bioactive endodontic cements followed by zirconia restauration, a bioinert ceramic material, milled using CAD/CAM technology. The preservation of pulp vitality using premixed bioceramic materials, ensures the continuation of dentinogenesis with its benefits, higher resistance of radicular walls against fracture, smaller diameter of apical foramen as well as creating conditions over time for a post retained crown with better aesthetic results.

Keywords: micro-pulpotomy, zirconia restauration, dental fracture

The purpose of the present paper is to describe the advantages of using the pre-mixed bioactive endodontic cements for pulpotomy procedures in a crown-root fracture with pulp exposure. Traumatic dental injuries (TDIs) occur frequently in children and young adults with a peak prevalence in the permanent dentition of boys aged 9-10 years old when sports and other outdoor activities start becoming more frequent. Crown-root fractures is the least occurring crown-related injury [1]. It involves the fracture of enamel, dentin and cementum, with or without pulpal involvement. The fracture usually starts at the mid-portion of the crown (facially) and extend below the gingival level (palatal), [2] but other designs are also possible. The coronal fragment is mobile, more or less displaced in incisal direction, with tenderness at percussion. Apical extension of fracture is usually not visible and periapical and occlusal radiographies are recommended. The recommended emergency treatment is a temporary stabilization of the loosed segment to adjacent teeth. Usually, these fractures occur in young teeth with open apices and it is therefore advantageous to preserve the pulp vitality using a partial pulpotomy. While most crown-root fractures are related to the survival of the affected teeth following different treatment procedures involving pulpectomy [3-5], there is little information regarding the preservation of pulp vitality in crown-root fractures.

Bioceramics are ceramic materials specifically designed for medical and dental use. They are classified as bioinert (non-interactive with biologic systems), biodegradable (soluble or resorbable, eventually replaced or incorporated into tissues) and bioactive (durable in tissues that can undergo interfacial interactions with surrounding tissue) [9,11]. Endodontic premixed bioceramics are bioactive materials with similar chemical composition: calcium silicates, calcium phosphate monobasic, zirconium oxide, tantalum oxide, fillers. They were developed by a Canadian research company in 2008 (Innovative BioCeramix, Inc., Vancouver Canada) since are available as EndoSequence ${ }^{\circledR}$ BC Sealer ${ }^{\mathrm{TM}}$, EndoSequence ${ }^{\circledR}$ BC RRM ${ }^{\mathrm{TM}}$ (Root Repair Material, syringable paste) and EndoSequence ${ }^{\circledR}$ BC RRM Fast Set Putty ${ }^{\mathrm{TM}}$. Recently FKG Dentaire Switzerland has marketed these materials as TotalFill ${ }^{\circledR}$ BC Sealer ${ }^{\mathrm{TM}}$, TotalFill ${ }^{\circledR}$ BC RRM Paste $^{\mathrm{TM}}$ and TotalFill ${ }^{\circledR}$ BC RRM Putty/Fast-Set Putty ${ }^{\mathrm{TM}}$.

The premixed bioceramics are not sensitive to moisture and blood contamination, dimensionally stable, slightly expandable, insoluble over time, have the advantage of uniform consistency and lack of waste. When unset, the premixed bioceramics have a $\mathrm{pH}$ above 12 and therefore antibacterial properties similar to calcium hydroxide. When fully set they are biocompatible and bioactive. When bioceramic materials make contact with tissue fluids they release calcium hydroxide which can interact with the phosphates in the tissues to form hydroxyapatite, showing the inductive properties of the material. The working time of the BC sealer and BC RRM is more than 30 min and the setting time is $4 \mathrm{~h}$, depending on the amount of moisture. The setting time of BC RRM Fast-Set Putty is approximately 20 min.

\section{Experimental part}

The patient, a 10-year-old boy was referred with a recent dental alveolar lesion (two hours) in the anterior teeth by falling. The clinical examination showed a complicated crown-root fracture with pulpal involvement and concussion in the maxillary left central incisor and an enamel crown fracture (mesio-incisal angle) in the maxillary right central incisor.

*email:cisaveanu@prevod.umfiasi.ro,daniulia05@yahoo.com, Phone.+40745 701535 
The clinical examination of the left maxillary central incisor showed a vestibular/ buccal, oblique fracture line, from the middle of incisal edge in mesial direction to the cervical line, extending below the gingival margin. From the oral surface, the fracture line was vertical, splitting the incisor in the middle and going from the incisal edge to the cervical line, also extending below the gingival margin $(5 \mathrm{~mm})$ (fig. $1 \mathrm{a}, \mathrm{b})$.

a)

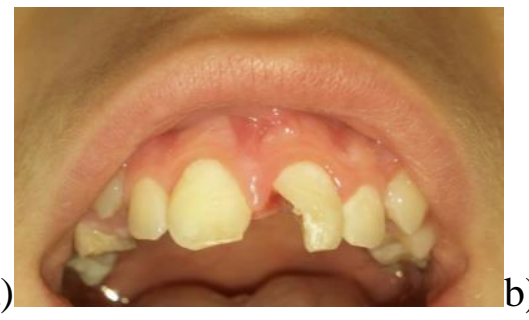

Fig. 1 Clinical aspects: a) vestibular view, oblique fracture direction b) palatal view, vertical fracture direction; c) crown-root fragment

The tooth was tender to touch, the coronal fragment was mobile, but it has not been displaced and did not have increased mobility. The percussion test showed tenderness. Sensitivity tests gave positive results. After the infiltration of non-vasoconstrictor anaesthesia - mepivacaine hydrochloride 1,7 ml (Mepivastesin ${ }^{\circledR} 3 \mathrm{M}$ ESPE) - the mobile crownroot fragment was removed (fig. $1 \mathrm{c}$ ) exposing the pulp of approximately six millimetres square.

"Miniature pulpotomy" was performed with minimal removal of vital pulp tissue following traumatic exposure [6]. Pulpal bleeding was controlled using sodium hypochlorite and after rinsing with a saline solution and gentle drying with sterile cotton pellets, the site was filled with premixed bioactive endodontic cement Total Fill ${ }^{\circledR}$ BC RRM Fast-Set Putty ${ }^{\mathrm{TM}}$ (FKG Dentaire Switzerland). The fractured fragment was ultrasonically cleaned in saline solution for 3 minutes at $30^{\circ} \mathrm{C}$ and dried with sterile cotton gauze. Total Fill ${ }^{\circledR} \mathrm{BC}$ Sealer ${ }^{\mathrm{TM}}$ was applied to both tooth surface and fragment surface. The fractured segment was then repositioned on the tooth until the original position has been re-established and maintained in this position for 20 minutes. Subsequently, teeth were splinted with flowable composite in the approximal areas and after one hour a fibre reinforced composite resin splint (Splint-It@Pentron) was placed on the vestibular/ buccal face and incisal edge of maxillary central incisors and left lateral incisor. It was easier than palatal splinting because the patient was no longer cooperative. Radiographic examination (Fig. 3a) confirmed that the two segments were a perfect fit [7].

Clinical and radiographic control were recommended after 3 months but the patient came after ten months when the tooth fragment has been dislocated (Fig.3b). The examination revealed an asymptomatic tooth, without discoloration and positive response to pulp testing. The colour of fractured segment was darker and the decision was to make an identical zirconia reconstruction using CAD/CAM technology, bonded with resin modified glass ionomer cement (GC FujiCEM ${ }^{\mathrm{TM}}$ 2) (fig $3 \mathrm{c}$ ). Orthodontic treatment was performed for the extrusion of the root so as to that the apical limit of the fracture line becomes supragingival ( $3 \mathrm{~mm}$ subgingival in the present) (fig $3 \mathrm{~d}$ ) concomitant with the progressive shortening of the incisal edge and which will be continued till the remaining root is sufficient length to support a postretained crown, if it will be necessary.

\section{Results and discussions}

The results in this case after three years and four months from the accident are satisfactory, the pulp is vital, asymptomatic, the zirconia restoration looks very good, without signs of gingivitis (Fig. 2 a, b, c).

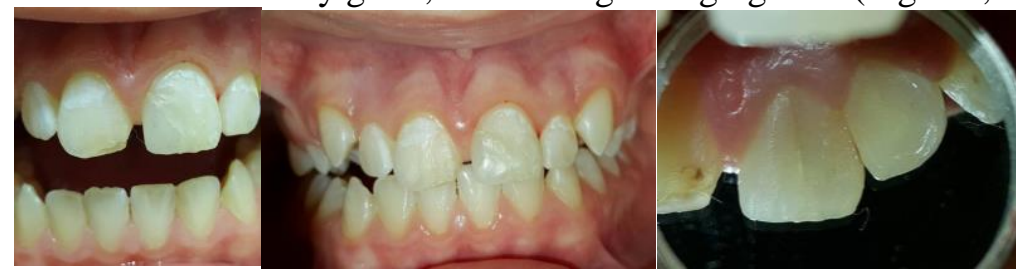

Fig. 2 Final outcome after 3 years: a),b) vestibular view; c) palatal view

Radiographic examination has not revealed signs of apical periodontitis (Fig $3 \mathrm{~b}, \mathrm{c}, \mathrm{d}$ ), that means it is a favourable outcome. In time, an unfavourable outcome may be a symptomatic tooth, or negative response to pulp testing, or signs of apical periodontitis, the existing studies drawing the attention to the difficulty to accurately establish a correct diagnosis based solely on clinical criteria [10]. 




Fig. 3 Postoperative radiographic evaluation: a) initial, after reattachment of crown-root fragment; b) after 10 months; c) after1 year, zirconia reconstruction, ; d) after 3 years, orthodontic extrusion

The decision to preserve the tooth and the pulp vitality was taken because is a young permanent tooth and the ideal treatment principles include the sealing of exposed dentinal tubules, protecting the pulp, encouraging reparative dentingenesis and restoring the tooth to its original function and aesthetics [2].

The choice of premixed bioceramics was made because their useful properties in this case with a subgingival line fracture and impossibility to use rubber dam and keep a dry surface. This material is a bioactive endodontic cement, hydrophilic, insoluble, radiopaque and requires moisture to set and harden. The working time for Total Fill ${ }^{\circledR}$ BC RRM Fast-Set Putty ${ }^{\mathrm{TM}}$ is approximately 20 min. Pre-mixed Total Fill ${ }^{\circledR}$ BC Sealer ${ }^{\mathrm{TM}}$ is the only pure medical-grade bio-ceramic product available, but it is less viscous [8,9]. It is not a bonding agent as it was used only for the protection of the pulp, the fixation of the fragments being purely mechanical through the splint.

For prosthetic restauration CAD/CAM method was chosen because of the difficulties of taking subgingival impression. The reconstruction materials taken into consideration were zirconia and nano-ceramic composite resin. Zirconia was chosen for its recommended luting cement, resin modified glass ionomer cement, which doesn't require etching and for its moisture tolerance. The orthodontic extrusion is recommended in order to avoid the leakage which can lead to the occurrence of subgingival caries with all its consequences ranging until the loss of the tooth. So, in time, if greater aesthetic restauration is required there are the conditions for bio-pulpectomy and a post-retained crown.

\section{Conclusions}

In the limit of this study we can concluded that the treatment of crown root fracture with pulp exposure is a challenge for specialists and a very debated subject. Premixed bioactive endodontic cements are the material of choice for pulp capping and pulpotomy, due to their biocompatibility, bioactivity, low cytotoxicity, sealing ability. The preservation of pulp vitality using premixed bioceramic materials, ensures the continuation of dentinogenesis with its benefits, higher resistance of radicular walls against fracture, smaller diameter of apical foramen as well as creating conditions over time for a post retained crown with better aesthetic results. Also, the tooth and the prosthetic reconstruction act as a space maintainer, more comfortable then any prosthetic piece with the advantage of bone preservation till there are conditions for an implant, if necessary.

\section{References}

1.GLENDOR U, HALLING A, ANDERSSON L, EILERT - PETERSSON E. Incidence of traumatic tooth injuries in children and adolescents in country of Västmanland Sweden. Swed Dent J 1996; 20:15-28

2.ANDREASEN JO, BAKLAND LK, FLORES MT, ANDREASEN FM, ANDERSSON L, Traumatic Dental Injuries. A manual, 3rd edition, Wiley Blackwell.

3.ANTHONY J. DIANGELIS, JENS O. ANDREASEN, KURT A. EBELESEDER, DAVID J. KENNY, MARTIN TROPE, ASGEIR SIGURDSSON, LARS ANDERSSON, CECILIA BOURGUIGNON, MARIE THERESE FLORES, MORRIS LAMAR HICKS, ANTONIO R. LENZI, BARBRO MALMGREN, ALEX J. MOULE, YANGO POHL, MITSUHIRO TSUKIBOSHI. International Association of Dental Traumatology guidelines for the management of traumatic dental injuries: 1. Fractures and luxations of permanent teeth. Dental Traumatology 2012; 28: 2-12; doi: 10.1111/j.1600-9657.2011. 01103.x

4.HAMDI CEM GÜNGÖR. Management of crown-related fractures in children: an update review. Dental Traumatology 2014; 30: 88-99; doi: 10.1111/edt.12079

5.POI WR, CARDOSO LC, CASTRO JCM, CINTRA LTA, GULINELLI JL, LAZARI JAB Multidisciplinary treatment approach for crown fracture and crown-root fracture -a case report. Dental Traumatology 2007; doi: 10.1111/j.1600-9657.2005. 00373.x

6.SAEED ASGARY AND MAHTA FAZLYAB Management of Complicated Crown Fracture with Miniature Pulpotomy: A Case Report. Iran Endod J. 2014 Summer; 9(3): 233-234.

7.GEORGIA V. MACEDO, PATRICIA I. DIAZ, CARLOS AUGUSTO DE O. FERNANDES, ANDRÉ V. RITTER. Reattachment of Anterior Teeth Fragments: A Conservative Approach.J Esthet Restor Dent 20:5-20, 2008.

8.TORABINEJAD M, PARIROKH M, DUMMER PMH. Mineral trioxide aggregate and other bioactive endodontic cements: an updated overview - part I: vital pulp therapy. Int Endod J. 2017 Aug 24. doi: 10.1111/iej.12841

9.GILBERTO DEBELIAN, MARTIN TROPE. The use of premixed bioceramic materials in endodontics. Giornale Italiano di Endodonzia (2016) $30,70-80$ 
10.CRISTIAN LEVENTE GIUROIU, IRINA-DRAGA CĂRUNTU, LUDMILA LOZNEANU, ANCA MELIAN, MARIA VATAMAN AND SORIN ANDRIAN. Dental pulp: correspondences and contradictions between clinical and histological diagnosis. Hindawi Publishing Corporation BioMed Research International, Volume 2015, Article ID 960321.

11.BEST SM, PORTER AE, THIAN ES, HUANG J. Bioceramics: past, present and for the future. J Eur Ceram Soc 2008; 28:1319-27.

Manuscript received: 30.10 .2019 